\title{
EDITORIAL
}

\section{A new team for Zoomorphology}

\author{
Andreas Schmidt-Rhaesa
}

Published online: 5 May 2012

(C) Springer-Verlag 2012

In 2003, Thomas Bartolomaeus took over as chief editor of the journal Zoomorphology, and after 9 years of intensive input, he handed over the editorship of the journal to me. In the name of the entire Editorial Board, I thank him very much for leading the journal through this period.

Being chief editor of a journal with such a tradition and with such a presence in the field of zoological morphology is a responsible and respectful task. Previous editors have done their best to establish the journal and respond to changes in the scientific community, for example by adjusting journal size, the title, the publishing language and so on. Zoomorphology has always put much emphasis on quality, both of text and of illustrations. This is essential for morphological publications and will continue to be an important topic.

Under Thomas Bartolomaeus as an editor, the impact of the journal grew continuously. Zoomorphology is one of the two leading journals dedicated to this field of research. A rich choice of manuscripts is received, confirming a high quality of the published ones.

I am looking back to a fascinating and impressive history of Zoomorphology, and I am honoured that trust is put into me to continue this important tradition. I am aware of the workload that an editorship of a journal like Zoomorphology creates. But I am curious and excited to take that task. This decision is made easy, because we have extended the team in the Editorial Board considerably. The term "dream team" is not far from being true. I am thankful for this team of experienced and enthusiastic colleagues. We cover a large area of expertise, in different animal taxa and in different techniques. Two past chief editors, Otto Kraus and Thomas Bartolomaeus, remain in the Editorial Board and share their experience with us.

I am also very thankful to the publisher Springer in Heidelberg for a good and productive atmosphere in the publishing process.

It is our aim to continue to publish high-quality papers in the area of morphology of multicellular animals. We offer our authors an open ear to their needs and try our best to keep the "throughput time" of manuscripts to a minimum. The coach of the recent German soccer champion said, looking back to the past season, that it was hard work, but no problem with a team like this. I am sure that I will be able to say something similar whenever looking back. But for now, I am looking forward to work with this new team for Zoomorphology!

\footnotetext{
A. Schmidt-Rhaesa ( $\square)$

Zoological Museum, University Hamburg,

Martin-Luther-King-Platz 3, 20146 Hamburg, Germany

e-mail: andreas.schmidt-rhaesa@uni-hamburg.de
} 